\title{
PENGARUH PERSEPSI MASYARAKAT TERHADAP PERMINTAAN KARTU KREDIT BERBASIS SYARIAH
}

\author{
Pahmi Nur Utami ${ }^{1}$, Anwar Rahim ${ }^{2}$, Abdullah Fathoni ${ }^{3}$
}

123 Universitas Ibn Khaldun Bogor, Indonesia

\begin{abstract}
This research aims to describe effect people perception though demand of Islamic credit card. This reseach uses interview and quisioner as analitic instrument with quantitative approach. The findings are first, knowledge about Islamic credit card on Islamic bank is most respondent don't known. And second, there are effect people perception though demand of Islamic credit card.
\end{abstract}

Kata kunci: Islamic credit card, perception 


\section{Pendahuluan}

Penggunaan kartu plastik di Indonesia masih relatif baru, namun sudah sangat luas digunakan sebagai instrument pembayaran sejak memasuki dekade 1980-an, dimana bisnis kartu kredit ini digolongkan sebagai kelompok usaha jasa. Kartu kredit (Credit Card) adalah alat pembayaran yang biasa digunakan dalam pembayaran suatu transaksi atau pengganti uang tunai. Sewaktu-waktu kartu kredit dapat digunakan untuk membeli/membayar apa saja yang kita inginkan pada tempat dimana saja yang dapat menerima kartu tersebut atau dapat juga diuangkan. Kartu kredit atau credit card merupakan sebuah gaya hidup dan bagian dari komunitas manusia untuk dapat dikategorikan modern dalam tata kehidupan sebuah kota yang beranjak menuju metropolitan atas cosmopolitan.

Kartu kredit pada hakikatnya adalah sebagai sarana mempermudah proses jual-beli yang tidak tergantung pada sistem pembayaran kontan, status hukun menurut fiqh kontemporer adaah sebagai objek jaminan atau media jasa jaminan (kafalah). Dan dalam hal ini dibolehkan berdasarkan Qs. Yusuf: 72.

Tentunya perjanjian atau akad yang mendasari penerbitan kartu kredit syariah ini berbeda dengan kartu kredit konvensional. Kalau dalam kartu kredit konvensional nasabah akan dikenakan bunga yang merupakan sumber utama pendapatan, maka dalam kartu kredit syariah nasabah tidak boleh dikenakan instrumen yang berupa bunga. Selain itu, kartu kredit syariah ini tidak boleh digunakan untuk transaksi yang tidak sesuai syariah, misalnya untuk transaksi di night club, dsb. Jika nasabah menggunakan kartu di tempat terlarang tersebut maka otomatis kartunya akan tertolak (decline) di mesin EDC.

Abdul Wahab Ibrahim Abu Sulaiman, Banking Cards Syariah Kartu Kredit dan Debet Dalam Perspektif Fiqih, Jakarta: PT Raja Grafindo Persada, 2006 , Edisi Ke-1, h.4 menyebutkan bahwa istilah kartu kredit yang tepat dalam bahasa Arab adalah bithaqah al-iqrad, karena istilah itu menunjukan kesesuaian terhadap hakikat kartu kredit tersebut, yang membedakannya dengan jenis kartu lain dari aspek persyaratan dan pelunasan pinjaman yang dibangun berdasarkan hukum syar'i.

Bank Indonesia (BI) masih ragu menerbitkan izin kartu kredit syariah. Alasannya, BI takut dampak negatif kartu kredit konvensional terjadi juga pada kartu kredit syariah. Menurut Peneliti Bank Eksekutif sekaligus Kepala Tim Riset dan Pengembangan Perbankan Syariah Direktorat Perbankan Syariah Bank Indonesia, Mulya E Siregar, pemegang kartu cenderung lebih konsumtif. Akhirnya, tagihan menumpuk dan nasabah sulit melunasi, itu terjadi karena plafon kredit yang diberikan jauh melalui pendapatan nasabah. "Kartu kredit cenderung membuat keuangan nasabah lebih besar pasak daripada tiang," ungkapnya. Ketua DSN MUI KH. Ma'ruf Amin berpendapat penggunaan kartu kredit harus dibatasi agar tidak menjurus pola konsumtif. Pendapatan dan transaksi atas barang halal menjadi patokan utama. "Kami minta bank mengawasi, kalau terjadi transaksi yang dilarang kartu kredit bisa dicabut," katanya.

Seiring maraknya penggunaan kartu kredit, ternyata bahasan tentang 
peluncuran kartu kredit syariah, akhirnya mendapat sedikit cahaya terang dari DSN (Dewan Syariah Nasional) MUI melalui fatwanya tentang kartu kredit syariah, fatwa Dewan Syariah Nasional (DSN) No.54/DSN-MUI/X/2006 mengenai Syariah Card dan surat persetujuan dari Bank Indonesia Undang-undang No. 7 tahun 1992 tentang Perbankan tersebut dinilai belum memberikan landasan hukum yang kuat terhadap perkembangan perbankan syariah di Indonesia, mengingat belum ada ketegasan pemberlakuan prinsip syariah.

Karena itu dengan melalui lembaran Negara Republik Indonesia Nomor 182 tanggal 10 November 1998 disahkan Undang- Undang No. 10 Tahun 1998 tentang Perbankan. Dikarenakan pengaturan mengenai perbankan syariah di dalam Undang-undang Nomor 7 Tahun 1992 tentang Perbankan sebagaimana telah diubah dengan Undang-Undang Nomor 10 Tahun 1998 belum spesifik sehingga perlu diatur secara khusus dalam suatu Undangundang itu sendiri, maka pada tahun 2008, diresmikanlah Undang-undang Nomor.21 Tahun 2008 tentang Perbankan Syariah, yang mengatur mengenai seluruh kegiatan perbankan syariah. Menimbang bahwa kebutuhan masyarakat Indonesia akan jasa-jasa perbankan syariah semakin meningkat, perbankan syariah juga memiliki kekhususan dibandingkan dengan perbankan konvensional, dan pengaturan mengenai perbankan syariah di dalam Undang undang Nomor 7 Tahun 1992 tentang Perbankan sebagaimana telah diubah dengan Undang-undang Nomor 10 Tahun 1998 belum spesifik sehingga perlu diatur secara khusus dalam suatu Undang-undang tersendiri.
Oleh karena hal ini maka diresmikan Undang-undang Nomor 21 Tahun 2008 tentang Perbankan Syariah. Dalam Undang-undang No.21 Tahun 2008, maka yang pengertian dari Bank Syariah adalah Bank yang menjalankan kegiatan usahanya berdasarkan prinsip syariah dan menurut jenisnya terdiri atas Bank Umum Syariah dan Bank Pembiayaan Rakyat Syariah (Pasal 1 angka 7). Bank Umum Syariah adalah bank syariah yang dalam kegiatannya memberikan jasa dalam lalu lintas pembayaran (Pasal 1 angka 8). Bank Pembiayaan Rakyat Syariah yang dalam kegiatannya tidak memberikan jasa dalam lalu lintas pembayaran (Pasal 1 angka 9).

Peraturan Bank Indonesia Nomor. 10/8/PBI/2008 Tentang Perubahan Atas Peraturan Bank Indonesia Nomor. 7/52/PBI/2005 tentang Penyelenggaraan Kegiatan Alat Pembayaran Dengan Menggunakan Kartu, Berdasarkan Pasal 1 angka 3 maka yang dimaksud dengan alat pembayaran dengan menggunakan kartu adalah alat pembayaran yang berupa kartu debet, kartu kredit, Automated Teller Machine (ATM), dan/atau kartu prabayar. Pengertian kartu kredit sendiri berdasarkan Pasal 1 angka 4 adalah alat pembayaran dengan menggunakan kartu yang dapat digunakan untuk melakukan pembayaran atas kewajiban yang timbul dari suatu kegiatan ekonomi, termasuk transaksi pembelanjaan dan/atau untuk melakukan penarikan tunai dimana kewajiban pembayaran pemegang kartu dipenuhi terlebih dahulu oleh acquirer atau penerbit, dan pemegang kartu berkewajiban melakukan pelunasan kewajiban pembayaran tersebut pada waktu yang telah disepakati baik secara sekaligus (charge card) ataupun secara angsuran. 
Penelitian ini membatasi bahasan pada: (a) Bagaimana persepsi dan pengetahuan masyarakat terhadap produk kartu kedit syariah? (b) Bagaimana pengaruh persepsi masyarakat terhadap permintaan kartu kredit syariah?

\section{Metode Penelitian}

Obyek penelitian atau populasinya adalah masyarakat sekitar Kecamatan Tanah Sareal Bogor. Dalam penelitian ini obyek penelitian adalah masyarakat sekitar sebanyak 200 responden. Dalam penelitian ini, teknik sampling yang digunakan adalah Simple Random Sampling. Metode pengumpulan data yang digunakan penulis dalam penelitian ini adalah: Penelitian Lapangan.

\section{HaSil ANALISIS DAN PEMBaHasan}

\section{A. Konsep Kartu Kredit Syariah}

Kartu Kredit Syariah telah diterbitkan oleh beberapa bank (seperti: BNI syariah, Danamon dan Niaga syariah ), kartu kredit ini sangat berbeda sekali dengan kartu kredit konvensional khususnya dalam sistem perhitungan biaya yang akan dibebankan kepada pemegang kartu kredit.

Pada kartu kredit konvensional, biaya bunga dan biaya-biaya lain (seperti biaya denda keterlambatan, dsbnya) yang timbul pada bulan tersebut, akan diakumulasi dengan sisa hutang pokok yang belum terbayarkan setelah tanggal jatuh tempo, untuk menghitung biaya bunga pada bulan berikutnya, sehingga dikenal dengan sistem bunga ber bunga (bunga yang dibungakan kembali). Selain itu perhitungan bunganya juga mulai dilihat berdasarkan nilai awal hutang pada saat transaksi dan juga melihat jumlah hari hutang yang berjalan, berdasarkan saldo hutang rata-rata harian, dihitung dari tanggal posting/ tanggal transaksi dan jika pada kartu kredit syariah Pada kartu kredit syariah card, sistem perhitungan biaya Monthly Fee.

Kartu kredit konvensional mengutamakanadanya bunga sebesar 2$4 \%$ per bulan sebagai bentuk pengambilan keuntungan terhadap pelunasan tagihan yang dicicil. Dan dalam kartu kredit konvensional jenis denda yang akan dikenakan bila pengguna terlambat melunasi hutangnya. Denda pertama adalah ta'widh, dan itu itu bukan bunga kemudian merupakan qardhul hasan yang akan disumbangkan ke BAZIS dan bukan hak bank.

Dalam kartu kredit syariah pun Pengguna wajib menyetor goodwill investment sebesar $10 \%$ dari limit. Ini bertujuan supaya penggunaan kartu kredit tidak semena-mena.

\section{B. Akad Kartu Kredit Syariah}

Akad kafalah dan aplikasinya dalam praktik produk kartu kredit, bank sebagai penerbit kartu bertindak sebagai penjamin (kafil) bagi pemegang kartu terhadap merchant atas semua kewajiban bayar (dayn) yang timbul dari transaksi antara pemegang kartu dengan merchant, dan atau penarikan tunai selain bank atau ATM bank Penerbit Kartu. Dengan demikan dapat dikatakan bahwa merchant bertindak sebagai pihak penerima jaminan dari bank berdasar prinsip kafalah. Atas pemberian kafalah ini, penerbit kartu dapat menerima fee (ujrah) dari pemegang kartu.

Aplikasi akad Ijarah dalam kartuk kredit syariah adalah biaya keanggotaan (iuran tahunan). Dalam akad ijarah ini penerbit kartu adalah penyedia jasa 
sistem pembayaran dan pelayanan terhadap pemegang kartu. Pemegang kartu dikenakan membership fee. Semua fee yang ditetapkan pada kartu kredit syariah harus dinyatakan jumlahnya pada saat akad aplikasi kartu secara jelas dan nilainya tetap, kecuali untuk merchant fee.

Ijarah sebagai suatu transaksi yang sifatnya saling tolong menolong mempunyai landasan yang kuat dalam al-Qur'an. Konsep ini mulai dikembangkan pada masa Khalifah Umar bin Khathab yaitu ketika adanya sistem bagian tanah dan adanya langkah revolusioner dari Khalifah Umar yang melarang pemberian tanah bagi kaum muslim di wilayah yang ditaklukkan. Dan sebagai langkah alternatif adalah membudidayakan tanah berdasarkan pembayaran kharaj dan jizyah.

Kebolehan transaksi ijarah didasarkan Al Qur'an QS. Az-Zukhruf 32 bahwa ini Allah menerangkan bahwa Allah telah membedakan hambaNya berkenaan dengan harta kekayaan, rezeki, akal, pemahaman, dan sebaginya yang merupakan kekuatan lahir dan batin, agar satu sama lain saling menggunakan potensinya dalam beramal, karena yang ini membutuhkan yang itu dan yang itu membutuhkan yang ini. Kemudian Allah menutup ayat dengan menegaskan bahwa apa-apa yang dirahmatkan Allah kepada para HambaNya adalah lebih baik bagi mereka dari pada apa-apa yang tergenggam dalam tangan mereka berupa pekerjaanpekerjaan dan kesenangan hidup duniawi.

Dan aplikasi akad Qardh dalam kartu kredit syariah adalah pemberian pinjaman untuk pengambilan tunai dalam akad qardh bank sebagai penerbit kartu bertindak selaku pemberi pinjaman (muqridh) kepada pemegang kartu (muqtaridh) melalui penarikan tunai dari bank atau ATM bank penerbit kartu. Madzhab Hanafi berpendapat, Qardh dibenarkan pada harta yang memiliki kesepadanan, yaitu harta yang perbedaan nilainya tidak meyolok, seperti barang-barang yang ditakar, ditimbang, biji-bijian yang memiliki ukuran serupa seperti kelapa, telur. Tidak diperbolehkan melakukan qardh atas harta yang tidak memiliki kesepadanan, baik yang bernilai seperti binatang, kayu dan agrarian, dan harta biji-bijian yang memiliki perbedaan menyolok, karena tidak mungkin mengembalikan dengan semisalnya. Karena menurut golongan ini, bahwa pinjam meminjam dengan sesuatu yang tidak dapat digantikan dengan yang serupa tidak diperbolehkan.

Akad qardh termasuk ke dalam akad tabarru', karena di dalamnya ada unsur menolong dalam kebaikan dan ketakwaan. Oleh sebab itu, muqridh berhak meminta agar harta yang dipinjam dikembalikan dengan segera. Akad qardh tidak boleh dilakukan secara tangguh agar terhindar dari ribâ alnâsiah. Namun, menurut Ulama Hanâfiyah, tangguh menjadi boleh dalam qardh karena menyangkut 3 hal : wasiat, ingkar janji, perintah pengadilan dan dalam hiwâlah

\section{Gambaran Umum}

Hasanah Card adalah produk dari BNI Syariah yang berupa produk berbasis syariah yang berfungsi seperti kartu kredit tetapi dengan sistem perhitungan yang lebih transparan, adil serta lebih ringan jika dibandingkan dengan kartu kredit konvensional. Kartu kredit ini merupakan produk yang 
dikeluarkan oleh pihak bank tertentu sehingga dapat digunakan pemiliknya untuk membeli barang dan segala keperluan dan pelayanan tertentu secara terhutang. Ketika Bank atau Lembaga Pembiayaan memberikan pinjaman uang kepada nasabah, pastinya Bank dan Lembaga pembiayaan tersebut menginginkan uangnya kembali. Karenanya, untuk memperkecil resiko (sebagai contoh, uangnya tidak kembali), dalam memberikan kredit. Bank atau Lembaga Pembiayaan harus mempertimbangkan beberapa hal terkait dengan itikad baik (willingness to pay) dan kemampuan pembayaran (ability to pay) nasabah untuk melunasi kembali pinjaman beserta bunganya. Hal tersebut terdiri dari 5C, yaitu Character (kepribadian), Capacity (kapasitas), Capital (modal), Colateral (jaminan) dan Condition of Economy (keadaan perekonomian).

Kartu kredit syariah ini merupakan kartu kredit yang dikeluarkan oleh bank yang berlandaskan syariah Islam. Pada dasarnya wujud dari kartu kredit syariah tidak beda jauh dari kartu kredit konvensional pada umumnya. Yang membedakan disini adalah mengenai mekanisme ketentuan dalam kartu kredit tersebut. Adapun beberapa ketentuan untuk kartu kredit syariah :

a. Tidak menimbulkan riba

b. Tidak digunakan untuk transaksi yang tidak sesuai dengan syariah

c. Tidak mendorong pengeluaran yang berlebihan (israf), dengan cara menetapkan pagu maksimal pembelanjaan

d. Pemegang kartu utama harus memiliki kemampuan finansial untuk melunasi pada waktunya e. Tidak memberikan fasilitas yang bertentangan dengan syariah

\section{Karakteristik Responden}

Jumlah responden lebih di dominasi oleh responden perempuan dengan jumlah 55\% dan sisanya laki-laki $45 \%$. Tingkat usia para responden lebih banyak yang berusia dibawah 40 tahun ada sebanyak 65\%. Dan yang diatas 40 tahun ada 70 responden atau sebesar $35 \%$.

Produk Hasanah card masih banyak masyarakat yang belum mengetahui keberadaannya dan belum mengenal,dengan jumlah persentase yang cukup tinggi $82 \%$ katagori tidak tahu, sebagian masyarakat masih ada yang belum percaya jika saat ini sudah ada kartu kredit yang sudah berlandaskan syariah seperti hasanah card.

Hal yang terpenting dari meningkatnya suatu produk yaitu dari sumber informasi yang di terima oleh para konsumen, dilihat dari tabel berikut, ada yang sudah pernah mendapat iformasi adanya produk kartu kredit syariah sebanyak 20,5\% , dan selebihnya $79,5 \%$ belum pernah mendapat infomasi mengenai kartu kredit syariah atau hasanah card.

Jumlah yang tidak mengetahui jenis akad yang digunakan ada 172 responden dengan persentase $86 \%$. Dan yang sudah mengetahui ada 28 responden dengan persentase 14\%. Nasabah yang mengetahui adanya biaya admin pada hasanah card hanya 19 responden dengan persentase 9,5\%, dan yang tidak mengetahui ada 181 responden dengan persentase $90,5 \%$. 


\section{E. Pengaruh Persepsi Masyarakat terhadap Permintaan Kartu Kredit Syariah}

Hipotesis yang penulis rumuskan seperti:

a. $\mathrm{H}_{\mathrm{a}}$ : adanya pengaruh dari persepsi masyarakat terhadap permintaan Hasanah Card, lebih tinggi $70 \%$ dari rata-rata nilai ideal

b. $\mathrm{H}_{0}$ : tidak adanya pengaruh dari persepsi masyarakat terhadap permintaan Hasanah Card, lebih rendah atau sama dengan $70 \%$ dari rata-rata nilai ideal.

Dan dalam penulisan hipotesis statistiknya seperti berikut:

$$
\begin{aligned}
& \mathrm{H}_{\mathrm{a}}: \mu_{1}<\mu_{2} \\
& \mathrm{H}_{\mathrm{o}}: \mu_{1} \leq \mu_{2}
\end{aligned}
$$

dan untuk taraf signifikan $\alpha=0,05$

Untuk kesimpulan yang bisa diambil dari uji $\mathrm{t}$ adalah $\mathrm{H}_{\mathrm{a}}$ : adanya pengaruh dari persepsi masyarakat terhadap permintaan Hasanah Card, lebih tinggi $70 \%$ dari rata-rata nilai ideal, sedangkan $\mathrm{H}_{\mathrm{o}}$ : tidak adanya pengaruh dari persepsi masyarakat terhadap permintaan Hasanah Card, lebih rendah atau sama dengan $70 \%$ dari rata-rata nilai ideal. Jadi sudah terlihat bahwa persepsi dari masyarakat memiliki pengaruh terhadap peningkatan permintaan kartu kredit syariah atau Hasanah card.

\section{KESIMPULAN}

Berdasarkan penelitian, analisis dan pembahasan di atas dapat ditarik beberapa kesimpulan:

1. Bahwa sebagian besar 200 responden yang menjadi sampel dalam penelitian ini dianggap dapat mewakili pendapat seluruh masyarakat yang ada di Kecamatan Tanah Sareal Bogor, yang menjadi objek penelitian dan lokasi penelitian penulis. Dapat dinyatakan bahwa persepsi dan pengetahuan masyarakat terhadap produk kartu kedit syariah masih sangat minim atau masih terdengar asing bahkan ada juga yang menyatakan mengapa syariah memiliki produk kartu kredit dan faktor yang mempengaruhi persepsi masyarakat yaitu faktor dari lingkungan msyarakat kemudian dipengaruhi juga oleh faktor psikologisnya. Dan dari quisioner yang telah disebah penulis hampir sebagian besar dari 200 responden memiliki persepsi Leniency dan persepsi Projection. Jika dilihat pada Gambar 4.9. Persentase Pengetahuan dari Hasanah card, sudah bisa dilihat jika untuk produk Hasanah card masih banyak masyarakat yang belum mengetahui keberadaannya dan belum mengenal,dengan jumlah persentase yang cukup tinggi 82\% katagori tidak tahu.

2. Dan pengaruh persepsi masyarakat terhadap permintaan kartu kredit syariah jelas ada pengaruhnya dari persepsi para masyarakat terhadap naiknya permintaan produk kartu kredit syariah yang dapat dilihat dari hasil uji $\mathrm{T}$ antara $\mathrm{t}$ hitung dan $\mathrm{t}$ tabel ternyata : $1,721<181$, maka $\mathrm{H}_{\mathrm{a}}$ diterima dan $\mathrm{H}_{\mathrm{o}}$ ditolak. $\mathrm{H}_{\mathrm{a}}$ : adanya pengaruh dari persepsi masyarakat terhadap permintaan Hasanah Card, lebih tinggi $70 \%$ dari rata-rata nilai ideal, jadi hal yang mempengaruhi adalah dari segi pengetahuan dan faktor kebutuhan. Hingga akhir 2013 jumlah cabang BNI Syariah mencapai 64 Kantor Cabang, 161 Kantor Cabang Pembantu, 17 Kantor Kas, 22 Mobil Layanan Gerak dan 20 Payment Point. Komitmen terhadap 
pemenuhan kebutuhan nasabah iB Hasanah Card juga diwujudkan melalui pemberian berbagai kemudahan, mulai dari fasilitas yang bersifat komersil berupa program cicilan, fasilitas yang bersifat ibadah seperti halnya program Umroh dan Qurban, hingga fasilitas yang bersifat sosial yang diwujudkan melalui program donasi untuk pendidikan

Sistem kartu kredit syariah yang digunakan oleh PT Bank BNI Syariah memiliki dasar pada fatwa DSN No. 54/DSN MUI/X/2006 dan surat persetujuan dari Bank Indonesia No. 10/337/DPbs tanggal 11-03-2008. Adapun untuk jenis produk kartu kredit ada beberapa jenis akad yang di gunakan dalam praktek transaksinya yaitu kafalah, qardh, dan ijarah. Sehingga dapat dikatakan bahwa sistem kartu kredit yang diterapkan oleh PT Bank BNI Syariah telah sesuai dengan apa yang ditetapkan dalam fatwa.

Di tengah kompetisi industri yang kian ketat, iB Hasanah Card menunjukkan bahwa prinsip syariah yang ditawarkannya mampu memberikan warna baru yang diminati. Hal ini terlihat dari prestasi positif yang ditunjukkannya. Sejak akuisisi pertamanya di tahun 2010, Ib Hasanah Card telah berhasil membukukan 200.000 kartu hingga akhir Desember 2013, dengan pertumbuhan kartu baru sebanyak 50.000 kartu di tahun tersebut.

\section{DAFTAR PUSTAKa}

Al-Qur'an dan terjemah, Bnadung : CV. Penerbit Diponegoro.

Abdurrahman, Hafiz, 2011, Hukum Islam Seputar Kartu Kredit, Bogor: AlAzhar Press.
Antonio , Muhammad Syafi'I, 2001, Bank Syariah dari Teori ke Praktek, Jakarta : Gema Insani.

Ascarya, 2007, Akad dan Produk Bank Syariah, Jakarta: PT. Raja Grafindo Persada.

Chaudhry, Muhammad Sharif, 2012, Sistem Ekonomi Islam Prinsip dasar, Jakarta: Kencana Edisi 1.

Djazuli, A. Yadi Janwari, LembagaLembaga Perekonomian Umat ( Sebuah Pengenalan), Jakarta: Raja Grafindo Persada, 2002.

Emzir, 2007, Metodologi Penelitian Pendidikan Kuantitatif dan Kualitatif, Jakarta: PT. Raja Grafindo Persada.

Firdaus, Muhammad, dkk, Cara Mudah Memahami Akad-Akad Syariah, Jakarta: Renaisan Creative, 2005.

Ghufron, \& Mas'adi, 2002, Fiqh Muamalah Kontekstual, Jakarta : PT Raja Grafindo Persada.

Hakim, Cecep Maskanul, 2011, Belajar Mudah Ekonomi Islam, Tangerang : Shuhuf Media Insani .

Hasan, Iqbal, 2004, Analisis Data Penelitian dengan Statistik, Jakarta: Bumi Aksara.

Hasan, M. Ali, 2003, Berbagai Macam Transaksi dalam Islam (Fiqh Muamalat), Jakarta : PT. Raja Grafindo Persada.

Ibdalsyah, \& Hendri Tanjung, 2014, Fiqih Muamalah Konsep dan Praktik, Bogor : Azam.

Ibrahim, Johanes, 2004, Kartu Kredit Dilematis Antara Kontrak dan Kejahatan, Bandung: Refika Aditama. 
Karim, Adiwarman, 2004, Bank islam Analisa Fiqh dan Keuangan, Jakarta : PT. Raja Grafindo Persada.

Prasetyo, Bambang, 2005, Metode Penelitian Kuantitatif: Teori dan Aplikasi, Jakarta: Rajawali Pers.

Pujiono, Arif , ISLAMIC CREDIT CARD (Suatu Kajian Terhadap Sistem Pembayaran Islam Kontemporer) , 19 Jul 2010, Jurnal Dinamika Pembangunan (JDP), Volume 2 (Nomor 1). pp. 6677. ISSN 1829- 7617.

Riduwan, 2010, Dasar-dasar Statistika , Bandung : Alfabeta.

Rodoni, Ahmad. Abdul hamid, Lembaga Keuangan Syariah, Jakarta: Zikrul Hakim,2008.

Sopiah, 2008, Perilaku Organisasi, Yogyakarta : CV. Andi Offset.

Subagyo, dkk., 2002, Bank dan Lembaga Keuangan Lainnya, Yogyakarta:

Sekolah Tinggi Ilmu Ekonomi YKPN.

Sudarsono, Heri, 2004, Bank dan Lembaga Keuangan Syariah Deskripsidan Ilustrasi, Yogyakarta : Ekonisia.

Sukmadinata, Nana Syaodih, 2002, Metodologi Penelitian Pendidikan, Bandung: PT. Remaja Rosdakarya.

Sulaiman, Abdul Wahab Ibrahin Abu, 2006. Banking Card Syariah Kartu Debit dan Kredit Dalam Perspektif Fiqh, Jakarta : PT. Raja Grafindo Persada.

Sunyoto, Danang \& Burhanudin, 2011, Perilaku Organisasi, Jakarta : PT. Buku Baru.

Sunyoto, Danang, 2012, Dasar-dasar Statistika Ekonomi, Yogyakarta: CAPS.
Suryohadibroto, Imam Prayogo \& Djoko Prakoso, 1995 , Surat Berharga : Alat Pembayaran Dalam Masyarakat Modern, Jakarta : PT. Rineka Cipta.

Tanjung, Hendri \& Abrista Devi, 2013, Metodologi Penelitian Ekonomi Islam, Jakarta : Gramata Publishing.

Tarmizi, Erwandi, 2013, Harta Haram Muamalat Kontemporer, Jakarta: Berkat Mulia InsaniEdisi ke 4

Toha, Miftah, 2003, Perilaku Organisasi Konsep Dasar dan Aplikasinya, Jakarta : PT. Raja Grafindo Persada.

Tunggal, Amin Widjaja, 1997, Kamus Manajemen Keuangan Dan Akuntansi Perbankan, Jakarta: PT Rineka Cipta.

Usman, Rahmat, 2002, Aspek-Aspek Hukum Perbankan Islam Di Indonesia, Bandung : PT. Citra Aditya Abadi.

Wibisono, Dermawan, 2013, Panduan Penyusunan Skripsi, Tesis \& Disertasi , Yogyakarta: CV. Andi Offset. 